\title{
DAILY RADIATION BUDGET OF THE BALTIC SEA SURFACE FROM SATELLITE DATA
}

\author{
Tomasz Zapadka ${ }^{a}$ \\ Adam Krężel ${ }^{\mathrm{b}}$ \\ Marcin Paszkuta ${ }^{\mathrm{b}}$ \\ Mirosław. Darecki ${ }^{c}$ \\ a) Pomeranian University in Słupsk, Institute of Physics, Poland \\ b)University of Gdańsk, Institute of Oceanography, Poland

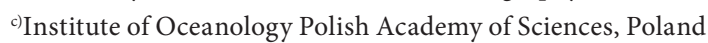

\begin{abstract}
Recently developed system for assessment of radiation budget for the Baltic Sea has been presented and verified. The system utilizes data from various sources: satellite, model and in situ measurements. It has been developed within the SatBattyk project (Satellite Monitoring of the Baltic Sea Environment - www.satbaltyk.eu) where the energy radiation budget is one of the key element. The SatBaltyk system generates daily maps of the all components of radiation budget on every day basis. We show the scheme of making daily maps, applied algorithms and empirical data collection within the system. An empirical verification of the system has been carried out based on empirical data collected on the oil rig placed on the Baltic Sea. This verification concerned all the components of the surface radiation budget. The average daily NET products are estimated with statistical error ca. $13 \mathrm{Wm}$-2. The biggest absolute statistical error is for LWd component and equals $14 \mathrm{Wm}$-2. The relative error in relation to the average annual values for whole Baltic is the biggest for SWu and reaches 25\%. All estimated components have correlation coefficient above 0.91 .
\end{abstract}

Keywords: Surface radiation budget, satellite, Baltic Sea

\section{INTRODUCTION}

The exchange of radiative energy between the atmosphere and the sea surface plays an important role in shaping the climate of the Baltic Sea. Monitoring of the radiation budget components at the sea surface allows to assess possible changes in the Baltic Sea environment and its directions. The surface radiative budget NET consists of four fluxes: downward $S W_{\mathrm{d}}$ and upward $S W_{\mathrm{u}}$ shortwave (solar radiation range $0.3 \mu \mathrm{m}-4 \mu \mathrm{m}$ ), and downward $L W_{\mathrm{d}}$ and upward $L W_{\mathrm{u}}$ (atmospheric and sea surface thermal radiation range $4 \mu \mathrm{m}$ - $100 \mu \mathrm{m}$ ) longwave radiation. The sum of all fluxes gives the surface radiation budget at surface NET. Details of these fluxes are shown on Fig.1.

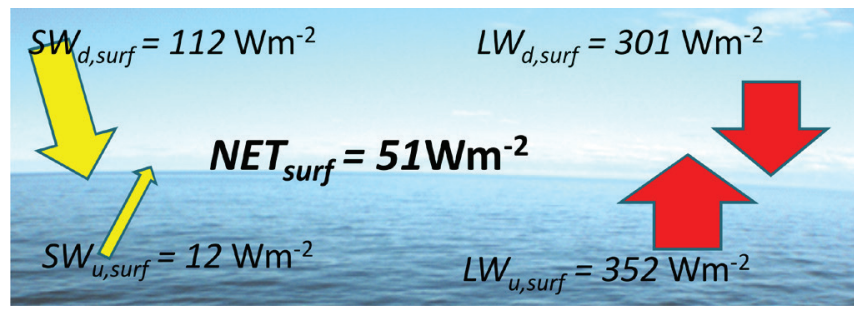

Fig. 1. Components of surface radiation budget with approximate values for the Baltic Sea estimated on the basis of data from SatBattyk system

For the Baltic Sea seasonal changes of the radiation budget at sea surface are calculated mainly based on numerical models [1], [9] or from hydro-meteorological ship observations 
[6]. The question of the energy budget of the Baltic Sea was developed within BALTEX (Baltic Sea Experiment [2], [3], [8], [12]). Depending on the model used, the final results are different [1], [9]. Due to the lack of direct measurements of the radiation fluxes at the sea, assessment of accuracy of such obtained data is very difficult. Therefore, other methods are desirable. Such a method commonly applied for many years is to assess radiative budget with the use of satellite observations. Satellite data allow the estimation of the surface radiation budget covering large areas at the one moment in time. Such estimations have been developed for many years by CM SAF (Climate Monitoring Satellite Application Facility on Ocean and Sea Ice) and OSI SAF (www.cmaf.eu, www.osi-saf.org). However, their study have a rather global character and possibilities of applying it to specific regions are often limited. In the SatBałtyk project [14], [15], local satellite algorithms have been used to create daily maps of radiation components. The algorithms were developed for the Baltic Sea [6], [16], [17] and improved within SatBałtyk project based on empirical data collected directly on the sea surface. The choice of satellite data source and appropriate algorithm determinates an accuracy of estimated values. In the case of a local area like the Baltic Sea, the space and time resolution of data used is also critical. It is important that the used algorithms have been developed specifically for this region. On the basis of these algorithms maps of radiation budget components are created every day and presented on the website http://satbaltyk.iopan.gda.pl/. The SatBałtyk project has launched actinometric stations along the Polish coast and one station on the oil rig placed around $70 \mathrm{~km}$ from shore. The data from the station at sea are very valuable and unique for the Baltic. The data enable to validate daily radiation budget components for real marine conditions for each day of the year. For the Baltic this type of analysis has not been conducted. Most of this type of validation was done on the basis of data from land stations or by indirect methods. The validations based on empirical data collected on the vessel have been made for instantaneous values [16].

The aim of this work is to show possibility of using satellite data to estimate the daily average of the surface radiation budget components for the Baltic Sea and to show accuracy of the presented methods. An empirical verification of the final products were carried out against empirical data from pyranometers and pyrgeometers placed on the oil rig [19]. The paper focuses on the overall scheme of modeling with emphasis on the type used input data and assessment of accuracy. Detailed information about the formulas used can be found in the cited papers [6], [16], [19] and in SatBałtyk project reports [18]. Most of them are still being modified and presented results should be treated as a preliminary.

\section{METHODS AND INPUT DATA}

Figure 2 shows the general block diagram for calculating components of the radiation budget. The input data come from the four independent sources: AVHRR (Advanced Very High Resolution Radiometer) radiometers working on board the
American TIROS-N/NOAA meteorological satellites (NOAA 15, 16, 17), SEVIRI (Spinning Enhanced Visible and InfraRed Imager) radiometer working on board MSG (Meteosat Second Generation 9, 10) and from prognostic model UMPL and from ecohydrodynamic model 3D CEMBS [4] as auxiliary data. The data from these sources are generated by SatBałtyk service. The maps from each source were imported into a $1 \mathrm{~km}$ resolution format $(1280 \times 1408$ pixels), in Lambert Azimuthal Equal Area projection. The final products have the same format. The main parameters determining the fluxes (sea surface temperature (SST), cloudiness) are defined based on satellite information. The SST were determined by using the split -window method for AVHRR thermal channels 10.8 $\mu \mathrm{m}$ and $12 \mu \mathrm{m}$ [5]. The number of SST maps was from six to eight for a day. Most of the maps were empty or only partially completed due to the presence of clouds. The cloudiness parameter was estimated separately for $S W_{\mathrm{d}}$ and for $L W_{\mathrm{d}}$ algorithms. This is due to the different properties of the $S W$ and $L W$ radiation. In the case $S W_{\mathrm{d}}$ cloudiness coefficient was determined based on HRV (High Resolution Visible 0.4-1.1 $\mu \mathrm{m})$ channel from SEVIRI [6]. In the case $L W_{\mathrm{d}}$ an impact of clouds on radiation reaching sea surface was determined by the functions of cloudiness different for night and daytime. For the daytime the function depends on HRV [18]. For the night the function is dependent on the cloud fraction parameter. Cloud fraction is determined based on thermal channels from SEVIRI [10].

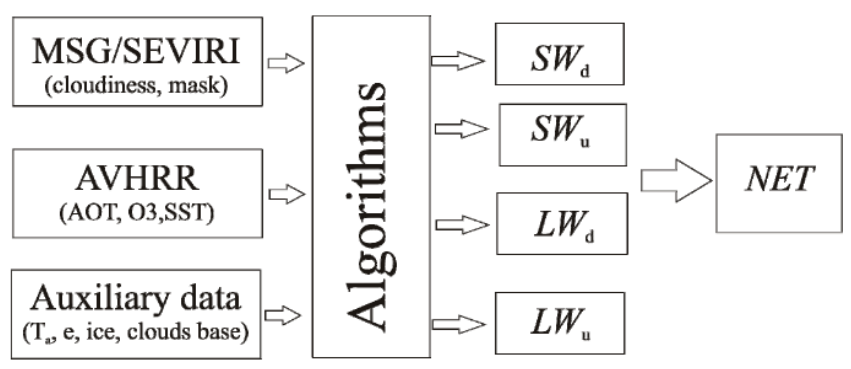

Fig. 2. Block diagram

The used models are described below. Most of them were developed or improved within the SatBałtyk project. The empirical data for satellite algorithms development were collected during cruises on s/y Oceania on the Baltic Sea in different seasons [16].

\section{DOWNWARD SHORTWAVE RADIATION $S W_{\text {D }}$}

The $S W_{\mathrm{d}}$ model described in detail by Krężel et al. [6] is a physical parametrization in which transmittances of the atmospheric column are computed separately for cloudless and cloudy situations. The model was developed within SatBałtyk project. For cloudless part $S W_{\mathrm{d}, 0}$ is computed by adding contributions from gaseous absorption, Rayleigh scattering and aerosols absorption and scattering. The model includes the absorption effect of the ozone (total ozone 
column daily from TOAST ${ }^{1} / \mathrm{NOAA}$ or OMI/Aura), the attenuation by aerosols (AOT - aerosol optical thickness of the atmosphere from AVHRR) and the water vapour content in the atmosphere (from UMPL model). The clouds transmission calculations is based on a cloudiness parameter from visible HRV channel from SEVIRI.

$$
S W_{d}=S W_{d, 0} T_{\text {cloud }}
$$

where $S W_{d, 0}$ - the irradiance for a cloudless atmosphere, $T_{\text {cloud }}$ - cloud transmittance computed on the basis of satellite algorithm as a function of cloudiness coefficient.

The instantaneous maps are computed every 15 minutes. Map of dose is created based on these maps. Both products are in the SatBałtyk operational service. The average daily maps are computed from:

$$
\overline{S W_{d}}=\frac{\sum_{t_{\text {sunrise }}}^{t_{\text {sunset }}} S W_{d}}{8640}
$$

where 8640 - the number of seconds in a day.

\section{UPWARD SHORTWAVE RADIATION $S W_{\mathrm{U}}$}

The $S W_{\mathrm{u}}$ flux is computed based on the function from Payne [11] modified by Rozwadowska [13] for Baltic Sea and developed in SatBałtyk project [19]:

$$
S W_{u}=S W_{d}\left\{\begin{array}{lll}
A_{\text {sea }} & \text { for } & \text { water } \\
A_{\text {ice }} & \text { for } & \text { ice }
\end{array}\right.
$$

where $A_{\text {sea, }} A_{\text {ice }}$ - sea and ice albedo dependent on the transmission of the atmosphere, solar zenith angle and ice thickness concentration.

The information about the ice concentration is taken from ecohydrodynamic model 3D CEMBS [4]. For ice areas albedo is calculated for melting ice, snow and pure ice.

The instantaneous $S W_{\mathrm{u}}$ maps are computed every 15 minutes and based on these maps, the daily average product is created:

$$
\overline{S W_{u}}=\frac{\sum_{t_{\text {sunrise }}}^{t_{\text {sunset }}} S W_{u}}{8640}
$$

\section{DOWNWARD LONGWAVE RADIATION $L W_{\mathrm{D}}$}

The $L W_{\mathrm{d}}$ model described in detail by Zapadka et al. [16], [17] is a semi-empirical formula which depends on water vapour $e$ concentration in the atmospheric column and greenhouse gases, air temperature at the sea surface and cloudiness. Air temperature $T_{\mathrm{a}}$ and water vapour $e$ were taken from the UMPL model. Cloud parameters were calculated separately for daytime (cloudiness from visible HRV channel

\footnotetext{
${ }^{1}$ Total Ozone Analysis using SBUV/2 and TOVS
}

from SEVIRI) and for night (cloud fraction as a combination IR channels from SEVIRI).

$$
L W_{d}=L W_{d, 0} f\left(c_{i}\right)
$$

where $L W_{d, 0}$ - the longwave irradiance for a cloudless atmosphere, $f\left(c_{i}\right)$ - a satellite cloud function different for night and daytime. The instantaneous maps are computed every hour and based on these maps, the average daily product is created. The average daily downward longwave radiation is calculated based on:

$$
\overline{L W_{d}}=\frac{\sum_{t=1}^{t=24} L W_{d, 0}}{n}
$$

where $n$ - number of maps.

\section{UPWARD LONGWAVE RADIATION $L W_{\mathrm{U}}$}

The $L W_{u}$ flux is computed on the basis of sea surface temperature $T_{S S T}$ obtained as a combination of two IR channels from AVHRR [5] and ice surface temperature $T_{i c e}$.

$$
L W_{u}=\left\{\begin{array}{l}
\varepsilon_{w} \sigma T_{S S T}^{4} \\
\varepsilon_{i c e} \sigma T_{i c e}^{4}
\end{array}\right.
$$

where $\varepsilon_{w}, \varepsilon_{i c e}$ - emissivity of the sea and ice surfaces respectively, $T_{S S T}$ - sea surface temperature from AVHRR and $T_{i c e}$ - ice surface temperature from the model.

The daily maps are created on the basis of all available scenes from up to five days back.

$$
\overline{L W_{u}}=\frac{\sum_{i=1}^{n} L W_{u}}{n}
$$

where $n$ - the number of cloudless pixels.

Almost $2 / 3$ of a year the sky over Baltic Sea area is covered by clouds. Obtaining the momentary temperature map for the whole Baltic Sea is not easy and requires analysing satellite maps from wider time range. Creating a satellite daily map for whole Baltic Sea often was done by merging many momentary maps. Used methodology gives a possibility to fill upward radiation map in $90 \%$ for almost 300 days a year [19].

\section{EMPIRICAL MATERIAL}

In this work we are presenting the verification of the mean daily values of every components. The verification was carried out against an empirical material collected in the years 2013 - 2014 on an actinometrical station located on the oil rig (PetroBaltic Platform on the Baltic Sea). The fluxes were measured using CG3, CGR4 pyrgeometers and CMP3 pyranometers (Kipp\&Zonen) with one minute time resolution. Data were averaged for every day. The database contains 250 days from September 2013 to September 2014 without February, half March, half June, July 2014. Gaps in the data are connected with a break in the measurements. However, 
the range of values can be considered as representative for the Southern Baltic. $S W_{d}$ changes from 6 to $370 \mathrm{Wm}^{-2}, S W_{u}$ from 4 to $26 \mathrm{Wm}^{-2}, L W_{d}$ from 255 to $392 \mathrm{Wm}^{-2}$ and $L W_{u}$ from 302 to $427 \mathrm{Wm}^{-2}$. In the Fig. 3 there is presented oil rig location on the background of exemplary NET map for $20^{\text {th }}$ September 2014. This figure shows a print screen taken from SatBałtyk website where one can find analyzed products. The analysis concerns one pixel within which the actinometrical station occurs.

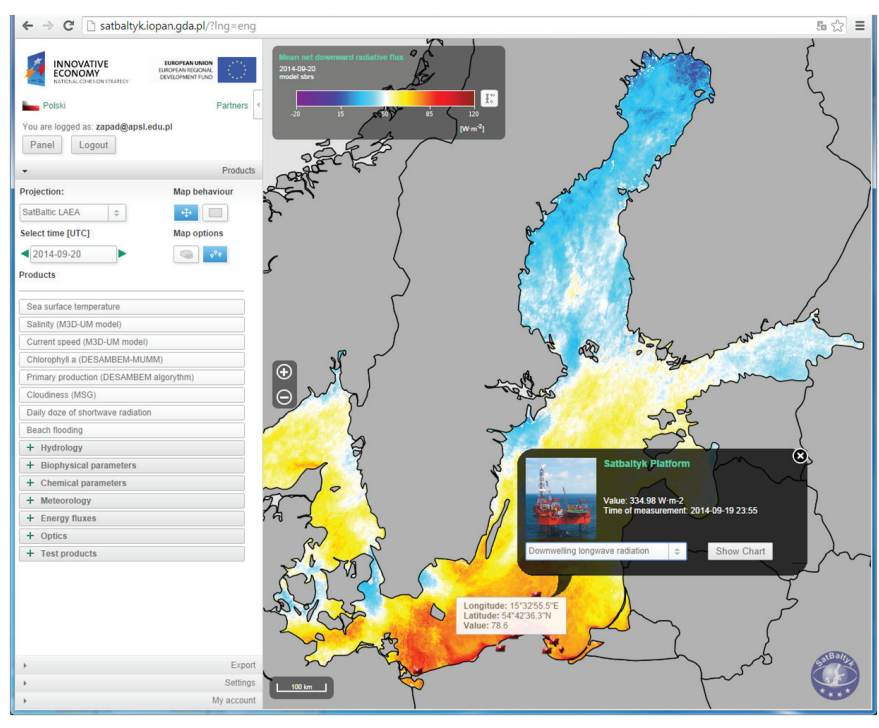

Fig. 3. Print screen from SatBaltyk website service with the oil rig localization

\section{RESULTS}

The methods described in paragraph 2 allow to create maps of each component of the radiation budget. The examples of daily average maps of $S W_{\mathrm{d}}, S W_{\mathrm{u}}, L W_{\mathrm{d}}, L W_{\mathrm{u}}$ for a chosen day $20^{\text {th }}$ September 2014 are shown in Fig. 4 . As one can see in the case of shortwave products $S W_{d}, S W_{u}$ distribution of values is similar but $S W_{\mathrm{u}}$ values are much smaller. It is because $S W_{\mathrm{u}}$ depends on $S W_{d}$. In the case of longwave radiation fluxes values, distribution differs and depends on many factors such as sea and atmosphere temperature, water vapour pressure and cloudiness. $L W_{\mathrm{u}}$ is usually smaller than $L W_{\mathrm{d}}$. The daily map NET (Fig. 5a) for $20^{\text {th }}$ September 2014 is a sum of four components where $L W_{\mathrm{u}}$ and $S W_{\mathrm{u}}$ are taken with the opposite sign. The smallest impact on the NET has $S W_{\mathrm{u}}$ but negligence of this variable could lead to big systematic errors especially in seasons of low sun position. The components are estimated with different accuracy. Comparisons between modelled and measured values of $S W_{\mathrm{d}}, S W_{\mathrm{u}}, L W_{\mathrm{d}}, L W_{\mathrm{u}}$ respectively are presented in Fig. 4 on the right side. The first plot concerns $S W_{\mathrm{d}}$. In this case, the correlation coefficient between the modeled and measured values is very high: $r=0.99$. Model works correctly in the whole range of values (for all seasons) with a slight underestimation of the value (systematic error - $2 \mathrm{Wm}^{-2}$ ). In the case of $S W_{u}$ the model works correctly for values below $20 \mathrm{Wm}^{-2}$. It means that for high positions of the sun model overestimates. For $L W_{\mathrm{d}}$ the spread of values is the biggest and the statistical error reaches $14 \mathrm{Wm}^{-2}$. The main reason of so high error is wrong interpretation of cloudless and cloudy situations. Moreover, this version of model does not use information on the height of the clouds base. This is important in the case of used cloud fraction parameter especially for the night. The statistical error of $L W_{\mathrm{u}}$ reaching $7 \mathrm{Wm}^{2}$ is associated with underestimating mask of clouds. This error occurs for the edge of clouds. For instantaneous values specially selected for cloudless sky $L W_{\mathrm{u}}$ is estimated with statistical error of $4 \mathrm{Wm}^{-2}$ [19].

Summarised results of empirical analysis are presented in Table I. The table contains statistical and systematic errors for each modelled component and correlation coefficients. Additional analysis was carried out for NET radiation balance. As one can see used model underestimates NET. Systematic error reaches value of $-3 \mathrm{Wm}^{-2}$. The relative error in relation to the average annual values for the whole Baltic is the highest for $S W_{\mathrm{u}}$ and reaches $25 \%$ and the lowest for $L W_{\mathrm{u}}-2 \%$. In other cases for $S W_{\mathrm{d}}$ this error reaches $9 \%$ and for $L W_{\mathrm{d}}-6 \%$.

a)

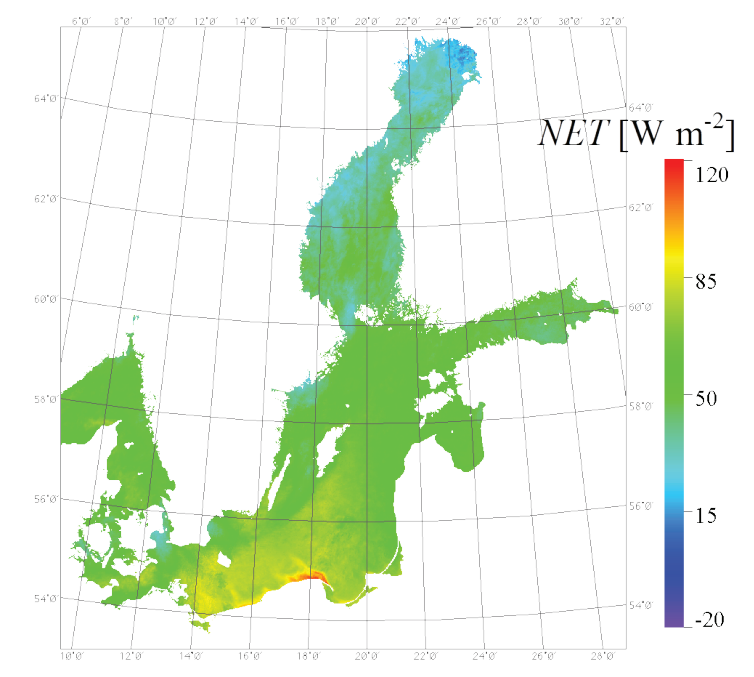

b)

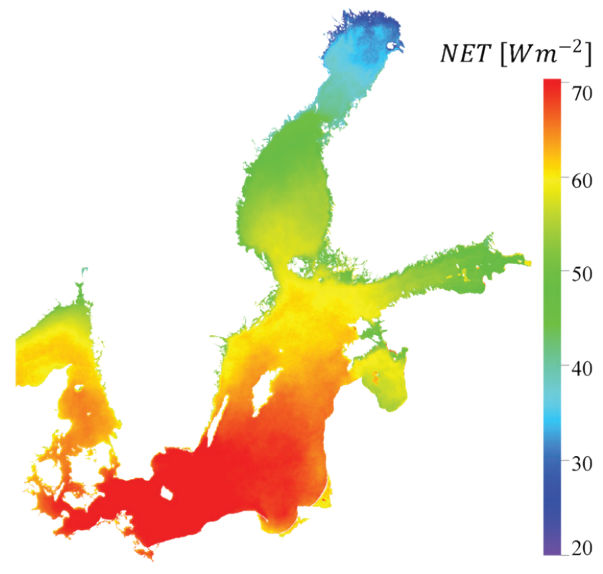

Fig. 5. The surface radiation budget NET for $20^{\text {th }}$ September (a) and for 2013 year average annual (b) 

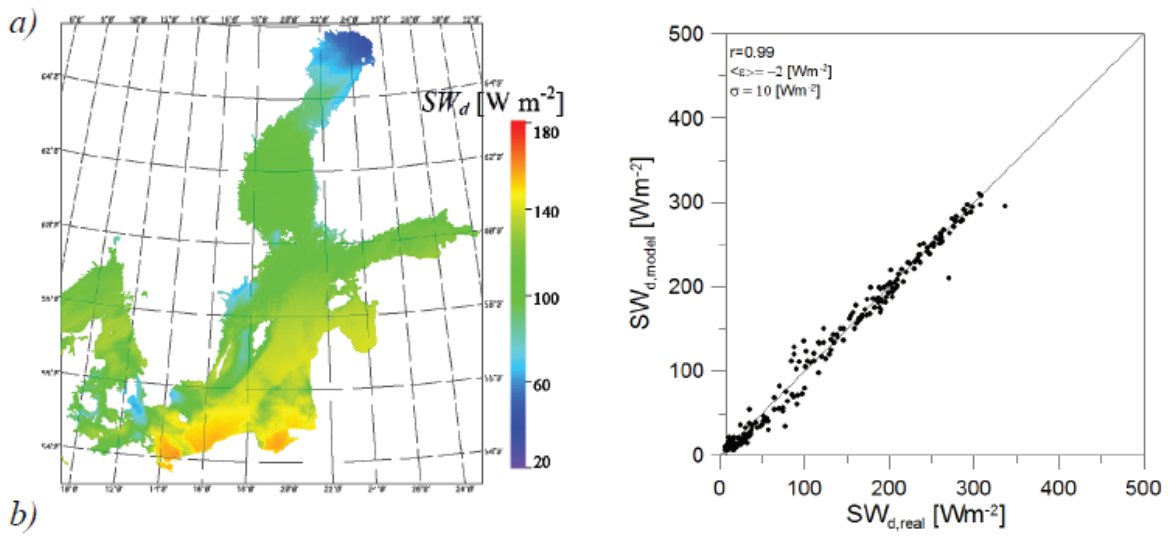

b)
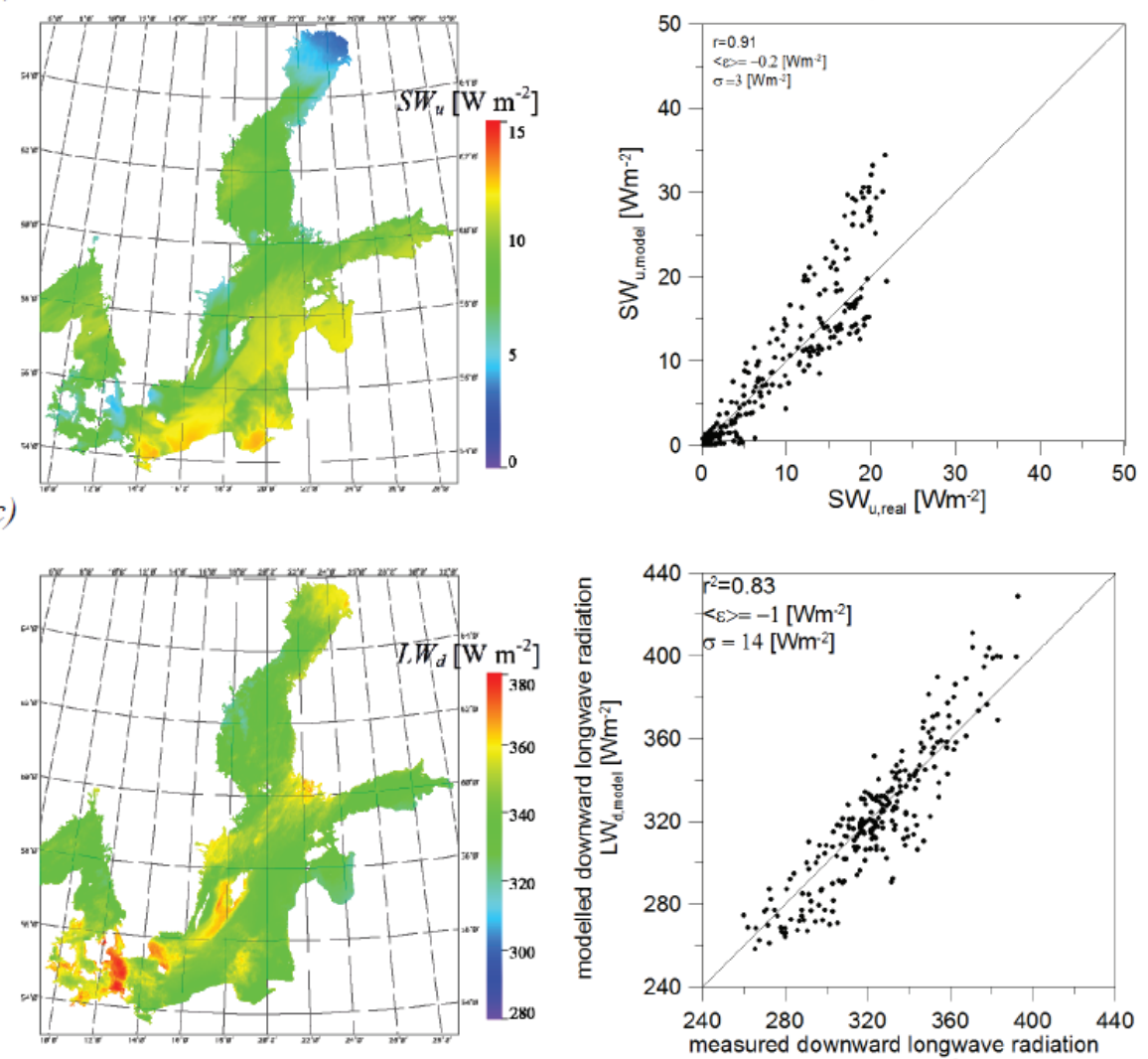

d)
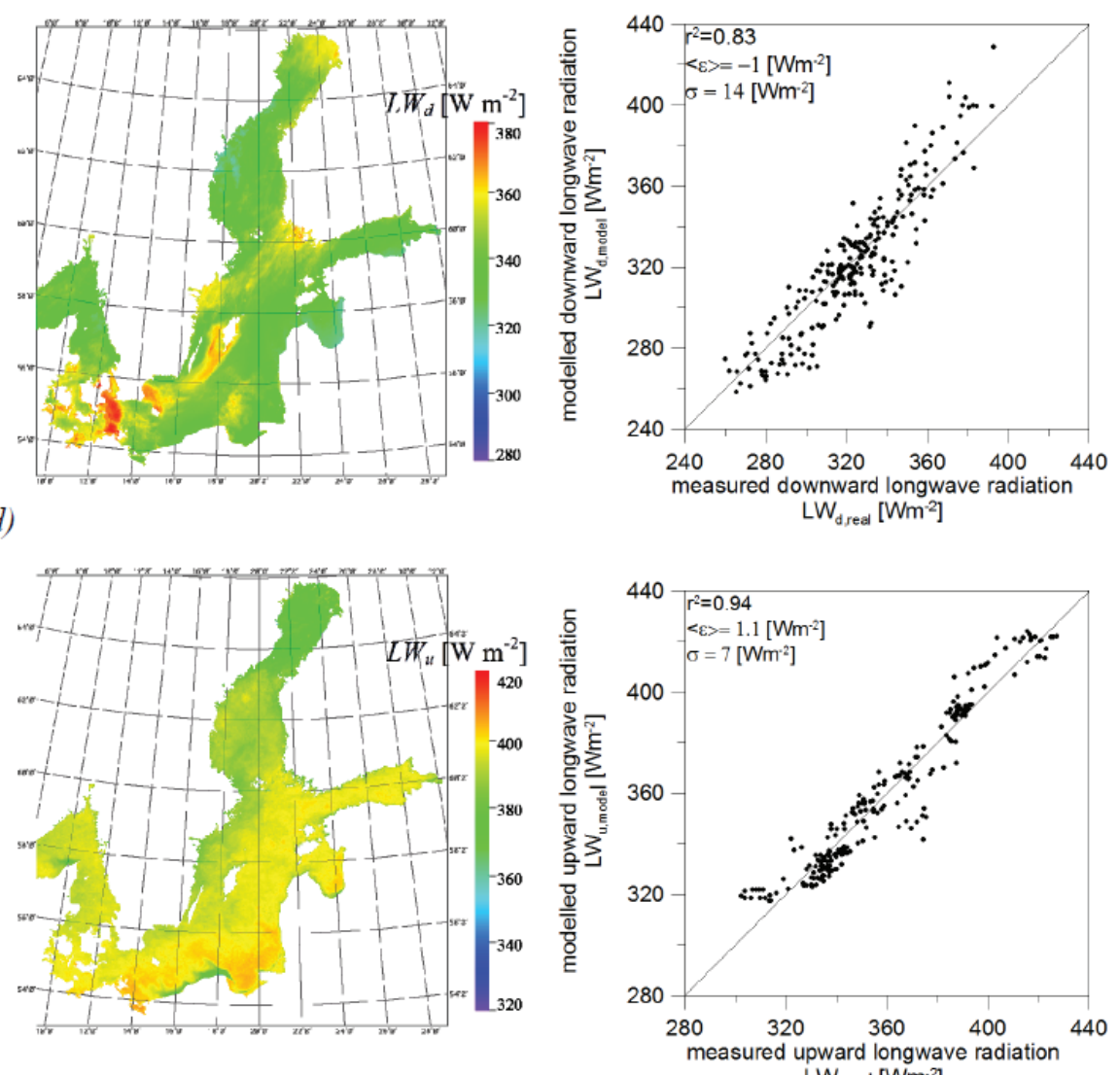

Fig 4. Daily average maps of $\left.\left.\left.S W_{d} a\right), S W_{u} b\right), L W_{d} c\right) L W_{u}$ d) for 20-09-2014, next to respectively for each flux comparisons between modelled and measured values 
Table 1. Validation of the components of the radiation budget (Statistic error - standard deviation and Systematic error - BIAS, Mean - average values for all database)

\begin{tabular}{|c|c|c|c|c|}
\hline flux & Mean & $\begin{array}{c}\text { Syst. error } \\
{\left[\mathrm{Wm}^{-2}\right]}\end{array}$ & $\begin{array}{c}\text { Stat. error } \\
{\left[\mathrm{Wm}^{-2}\right]}\end{array}$ & $\begin{array}{c}\text { Correlation } \\
\text { coefficient }\end{array}$ \\
\hline$S W_{d}$ & 139 & -1.8 & 10.0 & 0.99 \\
\hline$S W_{u}$ & 10 & -0.2 & 3.1 & 0.91 \\
\hline$L W_{d}$ & 323 & -1.3 & 14.2 & 0.91 \\
\hline$L W_{u}$ & 359 & 1.1 & 7.1 & 0.97 \\
\hline$N E T$ & & -3.0 & 13.0 & 0.98 \\
\hline
\end{tabular}

\section{CONCLUSIONS}

In presented work possibilities of estimating of the net radiation flux at the sea surface and its components $S W_{\mathrm{d}}$, $S W_{\mathrm{u}}, L W_{\mathrm{d}}, L W_{\mathrm{u}}$ for Baltic Sea elaborated within SatBałtyk project have been shown. We presented the scheme of creating daily maps and used algorithms. Described methods allow operationally to create maps of $S W_{\mathrm{d}}, S W_{\mathrm{u}}, L W_{\mathrm{d}}, L W_{\mathrm{u}}, N E T$ for one day and any time period (Fig. 4; Fig. 5). The algorithms operate on the basis of input data from SatBałtyk system. To a large part, their development depends on additional input data generated by SatBałtyk system.

The validation was carried out for every component based on empirical data collected at sea surface on the oil rig (Fig. 3). Such data are unique to the Baltic and the Earth. The empirical verification showed that presented method allows with a high accuracy to estimate radiation budget for the southern Baltic Sea region (table 1). Unfortunately, the lack of empirical data for typical areas covered with ice, does not allow assessment of upward components for northern regions of the Baltic. We realize that some algorithms still require some improvement, for example, of $L W_{\mathrm{d}}$ and $S W_{\mathrm{u}}$ models. In the first place the presented model requires improvement of a cloudiness function. In the $S W_{u}$ case the function of the solar elevation should be improved. $L W_{\mathrm{u}}$ dependence needs more correct mask of clouds.

The radiation budget at sea surface can be a key parameter for climate monitoring and analysis of the Baltic region. Satellite data allow estimation of the surface radiation budget with high spatial and time resolution. As shown, SatBałtyk system produce data which may be used to mentioned climate analysis. The daily map allows to analyse of spatial change of the surface radiation budget NET for every day in a year (Fig. 5a).The average annual map (Fig. 5b) shows the spatial distribution NET for the whole year.

\section{ACKNOWLEDGEMENT}

The study was supported by the Satellite Monitoring of the Baltic Sea Environment - the SatBałtyk project funded by the European Union through the European Regional Development Fund contract No. POIG 01.01.02-22-011/09.

\section{REFERENCE}

1. L. Bengtsson, Numerical modelling of the energy and water cycle of the Baltic Sea, Meteorology and Atmospheric Physics, 77, (2001); 9-17

2. BALTEX, BALTEX Phase I 1993-2002. State of the art report. BALTEX Secr. Publ., 31, (1977), 181 pp.

3. BALTEX, BALTEX Phase II 2003-2012. Science framework and implementation strategy, BALTEX Secr. Publ., 34, (2006a), 90 pp.

4. L. Dzierzbicka-Głowacka, M. Janecki, A. Nowicki, J. Jakacki, Activation of the operational ecohydrodynamic model (3D CEMBS)- the hydrodynamic part, Oceanologia, 55(3), (2013), 519-541

5. A. Krężel, M. Ostrowski, M. Szymelfenig, Sea surface temperature distribution during upwelling along the Polish Baltic coast, Oceanologia, 47(4), (2005), 415-432

6. A. Krężel, Ł. Kozłowski, M. Paszkuta, A simple model of light transmission through the atmosphere, Oceanologia, 50 (2), (2008), 125-146

7. R. Lindau, Energy and water budget of the Baltic Sea derived from merchant ship observation, Boreal Environ. Res., 7(4), (2002), 327-334

8. P. Lorenz, D. Jacob, BALTIMOS - a coupled modelling system for the Baltic Sea and its drainage basin, Theor. Appl. Climatol., 118, (2014), 715-727

9. A. Omstedt, Ch. Nohr, Calculating the water and heat balances of the Baltic Sea using ocean modelling and available meteorological, hydrological and ocean data, Tellus, 56A, (2004), 400-414

10. M. Paszkuta, Cloud detection and cloud fraction estimation, User manual - Final Report for SatBattyk POIG.01.01.0222-011/09, UG Gdynia, (2015), (in Polish)

11. R.E. Payne, Albedo of the sea surface, J. Atmos. Sci., 29, (1979), 959-970

12. M. Reckermann, J. Langner, A. Omstedt, H. von Storch, S. Keevallik, B. Schneider, B. Arheimer, M. Meier, B. Hünicke, BALTEX - an interdisciplinary research network for the Baltic Sea region, Environmental Research Letters, 6(4), (2011), 1-11

13. A. Rozwadowska, The variability in solar energy influx to the southern Baltic, Ph. D. thesis, Gdańsk Univ., Gdynia, (in Polish), (1992) 
14. B. Woźniak, K. Bradtke, M. Darecki, J. Dera, J. DudzińskaNowak, L. Dzierzbicka-Głowacka, D. Ficek, K. Furmańczyk, M. Kowalewski, A. Krężel, R. Majchrowski, M. Ostrowska, M. Paszkuta, J. Stoń-Egiert, M. Stramska, T. Zapadka: SatBaltic - a Baltic environmental satellite remote sensing system- an ongoing project in Poland. Part 1: Assumptions, scope and operating range, Oceanologia, 53(4),(2011), 897-924.

15. B. Woźniak, K. Bradtke, M. Darecki, J. Dera, J. DudzińskaNowak, L. Dzierzbicka-Głowacka, D. Ficek, K. Furmańczyk, M. Kowalewski, A. Krężel, R. Majchrowski, M. Ostrowska, M. Paszkuta, J. Stoń-Egiert, M. Stramska, T. Zapadka: SatBaltic - a Baltic environmental satellite remote sensing system- an ongoing project in Poland. Part 2: Practical applicability and preliminary results, Oceanologia, 53(4), (2011), 925-958.

16. T. Zapadka, B. Woźniak, J. Dera, A more accurate formula for calculating the net longwave radiation flux in the Baltic Sea, Oceanologia, 49(4), (2007), 449-470

17. T. Zapadka, A. Krężel, B. Woźniak, Longwave radiation budget at the Baltic Sea surface from satellite and atmospheric model data, Oceanologia, 50(2), (2008), 147-166

18. T. Zapadka, D. Stoltmann, The preliminary version of the algorithm to estimation the radiation budget components at the sea surface, User Manual-Report for SatBattyk POIG.01.01.02-22-011/09, AP Słupsk, (XII 2012), (in Polish)

19. T. Zapadka, D. Stoltmann, M. Paszkuta, The daily upward longwave radiation flux for Baltic Sea from MSG/SEVIRI data, 2013 Eumetsat Meteorological Satellite Conference; 19th American Meteorological Society(AMS) Satellite Meteorology, Oceanography, and Climatology Conference, 16-20 September (2013), Vienna, Austria

\section{CONTACT WITH THE AUTHOR}

T. Zapadka

Pomeranian University in Słupsk, Institute of Physics, Poland, ul. Arciszewskiego 22a, 76-200 Słupsk, Poland, e-mail: zapad@apsl.edu.pl

\section{A. Krężel}

University of Gdańsk, Institute of Oceanography, al. Marszałka Piłsudskiego 46, 81-378 Gdynia, Poland, e-mail: oceak@ug.edu.pl

\section{Paszkuta}

University of Gdańsk, Institute of Oceanography, al. Marszałka Piłsudskiego 46, 81-378 Gdynia, Poland, e-mail: ocempa@univ.gda.pl

\section{Darecki}

Institute of Oceanology Polish Academy of Sciences, ul. Powstańców Warszawy 55, 81-712 Sopot, Poland, e-mail: darecki@iopan.gda.pl

\section{Poland}

